\title{
Somatosensory Evoked Potentials in Neonates with Primary Congenital Hypothyroidism during the First Week of Therapy
}

\author{
COOT J. BONGERS-SCHOKKING, ERNST J. COLON, RICHARD A. HOOGLAND, \\ CORNELIS J. DE GROOT, AND J. LEO VAN DEN BRANDE \\ Department of Pediatrics, Zuiderziekenhuis, Rotterdam [C.J.B-S.]; Department of Psychiatry, Delta Hospital, \\ Rotterdam [E.J.C.]; Department of Pediatrics, Emma Kinderziekenhuis-Kinder AMC, Academic Medical Centre, \\ Amsterdam [C.J.d.G.]; and Department of Pediatrics, University Hospital for Children and Youth "Het \\ Wilhelmina Kinderziekenhuis," Utrecht, the Netherlands [J.L.V.d.B.]
}

\begin{abstract}
At the present, the influence of intrauterine hypothyroidism on the fetus is estimated by bone age (BA). $\mathrm{BA}$ is also used as a predictor of later neuropsychologic development. The aim of this study was to investigate whether the neurophysiologic maturation of neonates with congenital hypothyroidism (CHT) is delayed at the start of therapy and, if so, whether this delay is comparable to that in BA. Twenty-seven infants with CHT were examined with median nerve somatosensory evoked potentials (SEP) before or within 1 wk after initiation of therapy. The effect of neonatal jaundice, a potential confounder of neonatal SEP, was also evaluated. Cervical (N13), first cephalic (N19), and second cephalic (N32) peak latencies were measured, as well as N13-N19 interval (central conduction time) and N13 latency divided by arm length. The SEP data of 103 normal infants were used as reference values. In the CHT newborns, a maturational delay was found for all SEP parameters. Preterm infants $(n=3)$ were conspicuously less affected than term patients. In term CHT infants, jaundice during the first postnatal week, but not late jaundice, had an additional adverse effect. SEP delay was not related to initial or actual $\mathrm{T} 4$ levels. BA delay exceeded SEP delay by several weeks. Our data suggest that the depressed T4 levels of the hypothyroid fetus and neonate affect the nervous tissue to a lesser degree than bone tissue and, further, that SEP is superior to BA as parameter for the evaluation of neurologic maturation of infants with CHT. (Pediatr Res 30: 34-39, 1991)
\end{abstract}

Abbreviations

AL, arm length
BA, bone age
HT, hypothyroidism
CHT, congenital hypothyroidism
5'DI(II), iodothyronine 5'-deiodinase ty
EHB, early hyperbilirubinemia
GA, postmenstrual age at birth
LHB, late hyperbilirubinemia
NonHB, without EHB or LHB
PMA, postmenstrual age
SEP, somatosensory evoked potential
VEP, visual evoked potential
T4, thyroxine

Received December 8, 1989; accepted January 31, 1991

Correspondence and reprint requests: J. J. Bongers-Schokking, Department of Pediatrics, Zuiderziekenhuis, Groene Hilledijk 315, 3075 EA Rotterdam, the Netherlands.

Supported by Grant 28-1005 of the Praevention Fund, The Hague, the Netherlands.
T3, triiodothyronine

The postnatal development of the human brain has a critical period of several weeks of thyroid dependency. In CHT, treatment started after the age of $6 \mathrm{wk}$ leads to more intellectual and neurologic deficits than treatment started before $6 \mathrm{wk}$ of age $(1$, 2). But even in the group of early treated infants, defects are observed in fine motor coordination, concentration, speech, hearing, and learning (2-4). This may be the consequence of prenatal thyroid hormone deficiency, despite substantial transplacental transport of $\mathrm{T} 4$ to a CHT fetus (5). The lapse of time between birth and onset of therapy may be also a contributing factor, as well as perinatal complications such as asphyxia and jaundice, and inadequate substitution therapy (6).

Intrauterine $\mathrm{HT}$ may be evaluated by $\mathrm{BA}$ and initial thyroid hormone levels. However, there is uncertainty about the prognostic value of either of the two parameters for the final mental development of early treated CHT patients $(6,7)$. During the first week of life, the great majority of CHT infants show no neurologic abnormalities (8), but BA is frequently retarded. To gain insight into the maturation of the CNS of these infants, more specific methods reflecting the influence of HT on the CNS are needed. VEP, brainstem auditory evoked potential, and SEP have proved valuable in this respect in adult $\operatorname{HT}(9,10)$, as well as in untreated CHT infants $(11,12)$.

In our study, SEP measurements were used to investigate whether the neurophysiologic maturation of $\mathrm{CHT}$ infants before or within 1 wk after initiation of therapy was delayed and, if so, to what extent the delay was related to BA and initial and actual T4 levels. SEP are influenced by neonatal jaundice (13) in normal newborns. Because this is a frequent complication of CHT (14), the effect of jaundice was also evaluated in the $\mathrm{CHT}$ infants.

\section{SUBJECTS AND METHODS}

SEP measurements. Cervical (CS2-Fz) and cephalic $\left(\mathrm{C}^{\prime} / \mathrm{C}^{\prime}\right.$ Fz) SEP were recorded as described previously (15). Both arms were stimulated separately. The temperature of the arms was kept constant with a thermosensor fixed in the palm of one of the hands and a thermoelement above the arms, ensuring a near nerve temperature of $36-37^{\circ} \mathrm{C}$.

Recordings in newborns were made with a 2- to $100-\mathrm{Hz}$ filter bandpass only. In infants older than $1 \mathrm{wk}$, this filter was used as well, and for comparison a $2-$ to $2000-\mathrm{Hz}$ filter bandpass was used. The 2 - to $100-\mathrm{Hz}$ filter setting is appropriate for registration of both cephalic and cervical SEP in newborns (15). Calculations 
were performed using the $2-$ to $100-\mathrm{Hz}$ bandpass results only. For each recording, the results of 25-100 stimuli were averaged. Every recording was repeated to test reproducibility. Artefacts induced by movement were automatically rejected. The infants were either awake or in irregular sleep.

Latencies from the beginning of the stimulus to the peak of the first negativity in the cervical leads (N13) as well as to the peak of the first (N19) and second (N32) negativity in the cortical leads were measured. CCT was defined as the N13-N19 interval. N13/AL is the N13 latency divided by the arm length, i.e. half the distance from wrist to wrist (caput ulnae) in ventral supine position with the arms in $90^{\circ}$ abduction. For each parameter, the results from the right and left side were averaged.

Reference values. Reference data were obtained from SEP measurements of 103 normal infants with a PMA of 36-48 wk. The group consisted of 22 preterm infants $(\mathrm{GA}<36.5 \mathrm{wk})$ and 81 term infants $(\mathrm{GA} \geq 36.5 \mathrm{wk})$. The selection criteria for this group have been described previously (16). In essence, all infants were in good physical health, had been admitted to the pediatric ward for nonneurologic reasons, and had no major malformations, chromosomal abnormalities, serious illnesses, perinatal pathology, or abnormal thyroid screening results. For these reference data, the regression with PMA was determined. Linearity of the regression lines was obtained by logarithmic transformation of the SEP values. SEP lag (ms/m or $\mathrm{ms}$ ) was the observed value minus the expected value.

CHT patients. Twenty-seven infants (19 girls, eight boys) with primary CHT were studied. They were detected by the Dutch national $\mathrm{CHT}$ screening program. Besides $\mathrm{CHT}$, the patients had no other congenital abnormalities. In 10 infants, the diagnosis athyroidism was made. Another 10 patients had an ectopic thyroid gland and seven had an enzymatic defect in the thyroid hormone synthesis. GA of the infants ranged from 34 to $42.5 \mathrm{wk}$ and birth weight from 1910 to $4250 \mathrm{~g}$. All infants were born by vaginal delivery except one, who was delivered by cesarean section. The Apgar scores after 1 min were above 6 in all cases. Four patients (GA 34-37 wk) had respiratory difficulties. One of these needed a 3-d period of assisted ventilation.

Mean age at the onset of therapy was $20 \pm 6 \mathrm{~d}$ (mean $\pm 1 \mathrm{SD})$. Therapy consisted of either $5-8 \mu \mathrm{g} / \mathrm{kg} \mathrm{L}-\mathrm{T} 4(n=23)$ or $3 \mu \mathrm{g} / \mathrm{kg}$ T3 $(n=4)$ in progressive doses. Because it was considered unethical to postpone treatment in favor of the SEP test, organizational and technical reasons precluded measurement of all infants before the onset of therapy. Thirteen patients were tested at the onset and 14 within 1 wk after initiation of therapy, at $2.5 \pm 2.1 \mathrm{~d}$. This was not considered to introduce an important bias because SEP changes do not follow changes in thyroid hormone levels directly, but within a time interval of at least 1 wk $(10-12)$. Before each test informed consent was obtained from the parents. The project was approved by the ethical committee of the hospital.

After logarithmic transformation, the regression lines of the SEP variables with PMA were estimated. The relations of SEP lag with BA lag and initial and actual T4 were determined. The influence of age was evaluated by comparison of the results of the preterm and term patients by variance analysis (17). The distance along the $x$-axis between the estimated regression lines of CHT and reference infants is a linear function of PMA. This distance (dSEP, in weeks) was determined for each SEP parameter, as well as for BA (dBA).

$B A$ and thyroid hormones. BA was determined with the method of Sénécal et al. (18), which is based on the appearance of five ossified bone centers in the knee and ankle. BA is expressed in scores and increases linearly from 5 at $30 \mathrm{wk}$ to 12.5 at 45 wk PMA. T4 (nmol/L) was determined in serum at the onset of therapy (initial T4) and at the day of testing (actual T4). Serum TSH concentration was above $60 \mathrm{mU} / \mathrm{L}$ in all CHT infants, with the exception of one infant who had a defect of thyroid globulin synthesis and a TSH of $29 \mathrm{mU} / \mathrm{L}$.

Hyperbilirubinemia. CHT patients were divided into groups according to the type of jaundice: EHB (maximum bilirubin value above $250 \mu \mathrm{mol} / \mathrm{L}$ during the first week), late jaundice (LHB) (bilirubin above $170 \mu \mathrm{mol} / \mathrm{L}$ after $10 \mathrm{~d}$ ), or absence of both kinds of jaundice (NonHB). The CHT/NonHB group contained 11 infants (Table 1) and the CHT/LHB group consisted of eight neonates with bilirubin levels at the onset of therapy of $272 \pm 92 \mu \mathrm{mol} / \mathrm{L}$. No preterm infants were present in these two groups. The $\mathrm{CHT} / \mathrm{EHB}$ group contained eight newborns, three preterm (preterm CHT/EHB group, maximum bilirubin $255 \pm$ $5 \mu \mathrm{mol} / \mathrm{L}$ ), and five term patients (term $\mathrm{CHT} / \mathrm{EHB}$ group, maximum bilirubin $295 \pm 55 \mu \mathrm{mol} / \mathrm{L}$ ). All were treated with phototherapy, one of them with exchange transfusion. The SEP lags of the CHT groups were compared by means of a variance analysis (17).

The interaction of early jaundice and CHT on the SEP values was evaluated by factor analysis in a $2 * 2 * 4$ contingency table with four groups of term infants: with and without $\mathrm{CHT}$, and with and without $\mathrm{EHB}$. The groups with $\mathrm{CHT}$ were identical to the term CHT/EHB and CHT/NonHB groups; those without CHT consisted of two groups of normal infants. The first (control/EHB, $n=10$, maximum bilirubin $313 \pm 52 \mu \mathrm{mol} / \mathrm{L}$, PMA $44.0 \pm 1.4 \mathrm{wk}$ ) was included in an earlier study (14). For the second group (control/NonHB, $n=18$, PMA $44.2 \pm 1.5 \mathrm{wk}$ ), all term infants were selected from the reference group with a postnatal age of $2 \mathrm{wk}$ or more and a PMA in the same range as the CHT/EHB and CHT/NonHB groups (40.9-47.8 wk, Table 1). The influence of these factors (CHT, EHB, and the various SEP parameters) alone and in combination was tested (17).

\section{RESULTS}

Reference population. The reference group showed decreasing SEP latencies between 36 and 48 wk PMA (Fig. 1). The slopes of the regression lines were different for the various parameters $(p<0.001)$.

CHT infants. The SEP data obtained for the CHT infants are shown in Figure 1 and listed in Table 1. A significant delay was found for all SEP parameters (Table 2). The four SEP variables were uniformly affected. The SEP lag was independent of initial or actual T4. The preterm CHT patients had less delayed SEP values than the term infants $(F(1 ; 100)=16.90, p<0.005)$. All parameters correlated inversely with PMA (N13/AL: $r=-0.80$, N19: $r=-0.61$, CCT: $r=-0.71$, and N32: $r=-0.77 ; p<$ 0.0001 for all) (Fig. 1). The regression coefficients of two parameters (N13/AL and N19) were significantly different from those of the reference population ( $p<0.025$ for both). The mean PMA was $43.1 \pm 2.5 \mathrm{wk}$. At this age, dSEP was on the order of 2-3 wk for all variables (Table 2).

$\mathrm{BA}$ score of the CHT infants was $8.3 \pm 2.4$, whereas $11.6 \pm$ 1.7 is normal for this age (18). dBA was $6.4 \pm 0.6 \mathrm{wk}$ (Table 2). This value was larger than any of the dSEP values. BA lag correlated with initial T4 $(r=-0.52, p<0.05)$, but not with PMA or the lag of any of the SEP variables.

Hyperbilirubinemia. The CHT/NonHB, CHT/LHB, and term CHT/EHB groups all showed delayed SEP values (Table 3). The differences between the CHT/NonHB and the CHT/LHB group were not significant. The SEP lag of the term CHT/EHB infants exceeded that of the CHT/NonHB neonates $[F(\mathrm{v}=1 ; 56)=$ $15.43, p<0.005]$. In the same way, the SEP lag of the control/ EHB group was larger than that of the control/NonHB group $[F(\mathrm{v}=1 ; 100)=9.45, p<0.005]$. Factor analysis identified CHT and EHB as determining factors [CHT: $F(\mathrm{v}=1 ; 160)=$ $37.10, p<0.005$; EHB: $F=12.16, p<0.005$ ]. No consistent difference could be established between the four leads $(F=1.85$, NS). The effects of EHB and CHT were independent of each other $(F=1.75$, NS).

Wave form. The preterm cephalic wave form was characterized by a large negative deflection that comprised both the N19 and N32 peaks (Fig. 2). At later ages these negativities became steeper and better defined, due to the appearance of a positive deflection 
Table 1. Clinical and SEP data of CHT infants, grouped according to type of jaundice

\begin{tabular}{|c|c|c|c|c|c|c|c|c|c|c|c|}
\hline & $\begin{array}{l}\text { GA } \\
(w k)\end{array}$ & $\begin{array}{l}\text { PMA } \\
\text { (wk) }\end{array}$ & $\begin{array}{c}\begin{array}{c}\text { Bili* } \\
(\mu \mathrm{mol} / \mathrm{L})\end{array} \\
\end{array}$ & $\begin{array}{c}\text { Type } \\
\text { CHT } \dagger\end{array}$ & $\begin{array}{c}\mathrm{T} 4 \\
(\mathrm{nmol} / \mathrm{L})\end{array}$ & $\begin{array}{c}\text { TSH } \\
(\mathrm{mU} / \mathrm{L})\end{array}$ & $\begin{array}{c}\text { BA } \\
\text { score }\end{array}$ & $\begin{array}{c}\text { N13/AL } \\
(\mathrm{ms})\end{array}$ & $\begin{array}{l}\text { N19 } \\
\text { (ms) }\end{array}$ & $\begin{array}{c}\mathrm{CCT} \ddagger \\
(\mathrm{ms})\end{array}$ & $\begin{array}{l}\mathrm{N} 32 \\
(\mathrm{~ms})\end{array}$ \\
\hline \multicolumn{12}{|c|}{ CHT/NonHB $(n=11)$} \\
\hline 1 & 39.0 & 41.6 & & $\mathrm{E}$ & 51 & $>60$ & 8.0 & 51.8 & 34.2 & 22.7 & 71.0 \\
\hline 2 & 40.0 & 43.3 & & TB & 17 & 180 & 6.0 & 50.8 & 27.9 & 17.0 & 56.0 \\
\hline 3 & 39.0 & 42.1 & & $\mathrm{~PB}$ & 60 & 176 & 10.8 & 52.1 & 26.2 & 15.7 & 55.0 \\
\hline 4 & 41.0 & 43.6 & & A & 19 & 200 & 7.3 & 52.1 & 35.6 & 24.9 & 66.0 \\
\hline 5 & 40.0 & 43.6 & & A & 27 & 480 & 10.3 & 51.8 & 28.8 & 18.2 & 60.0 \\
\hline 6 & 42.0 & 44.9 & & $\mathrm{E}$ & 110 & $>60$ & 12.0 & 50.1 & 28.0 & 17.1 & 57.0 \\
\hline 7 & 41.0 & 45.0 & & PB & 95 & 93 & 11.5 & 51.4 & 25.8 & 14.7 & 53.5 \\
\hline 8 & 41.0 & 44.0 & & A & 22 & 1000 & 5.3 & 52.6 & 26.0 & 15.1 & 55.0 \\
\hline 9 & 42.0 & 44.6 & & $\mathrm{E}$ & 31 & 185 & 10.3 & 48.6 & 28.2 & 17.6 & 57.0 \\
\hline 10 & 40.0 & 42.0 & & PB & 70 & 115 & 6.8 & 53.9 & 31.2 & 19.7 & 59.8 \\
\hline 11 & 42.5 & 47.8 & & $\mathrm{E}$ & 85 & $>60$ & 12.5 & 51.6 & 25.0 & 13.9 & 50.0 \\
\hline Mean & 40.7 & 43.9 & & & 53 & $>237$ & 9.2 & 51.5 & 28.8 & 17.9 & 58.0 \\
\hline SD & 1.2 & 1.7 & & & 33 & & 2.6 & 1.4 & 3.5 & 3.4 & 5.7 \\
\hline \multicolumn{12}{|c|}{$\mathrm{CHT} / \mathrm{LHB}(n=8)$} \\
\hline 12 & 40.0 & 42.6 & 225 & $\mathrm{E}$ & 32 & 300 & 9.0 & 57.1 & 35.0 & 23.1 & 64.0 \\
\hline 13 & 42.0 & 46.0 & 310 & $\mathrm{~TB}$ & 13 & 254 & 7.2 & 49.8 & 26.2 & 15.8 & 57.0 \\
\hline 14 & 42.0 & 44.4 & 180 & $\mathrm{~A}$ & 13 & 254 & 6.0 & 55.9 & 30.0 & 18.3 & 62.5 \\
\hline 15 & 42.0 & 45.0 & 212 & A & 29 & $>75$ & 6.0 & 48.3 & 30.0 & 15.3 & 62.5 \\
\hline 16 & 42.0 & 44.1 & 200 & $\mathrm{E}$ & 40 & $>60$ & 11.0 & 48.3 & 25.6 & 15.0 & 62.0 \\
\hline 17 & 42.0 & 44.4 & 350 & A & 12 & 300 & 6.0 & 52.9 & 28.2 & 16.8 & 54.0 \\
\hline 18 & 41.0 & 44.1 & 313 & $\mathrm{E}$ & 60 & 314 & 8.5 & 50.7 & 26.2 & 15.4 & 62.0 \\
\hline 19 & 40.0 & 42.6 & 360 & $\mathrm{~TB}$ & 18 & 1000 & 6.5 & 55.0 & 31.2 & 19.8 & 61.0 \\
\hline Mean & 41.1 & 44.1 & 272 & & 27 & $>305$ & 7.5 & 52.3 & 29.1 & 17.4 & 60.6 \\
\hline SD & 0.9 & 1.1 & 75 & & 17 & & 1.8 & 3.4 & 3.2 & 2.8 & 3.4 \\
\hline \multicolumn{12}{|c|}{ Term CHT/EHB $(n=5)$} \\
\hline 20 & 42.0 & 44.7 & 294 & A & 12 & 500 & 8.5 & 53.8 & 32.4 & 21.5 & 69.0 \\
\hline 21 & 38.0 & 43.7 & 267 & PB & 71 & 29 & 12.0 & 51.5 & 30.0 & 18.9 & 56.0 \\
\hline 22 & 37.0 & 40.9 & 390 & $\mathrm{E}$ & 28 & 240 & 10.5 & 60.8 & 49.2 & 37.1 & 108.4 \\
\hline 23 & 40.0 & 41.9 & 256 & $E$ & 39 & 378 & 6.0 & 52.3 & 33.6 & 22.5 & 72.0 \\
\hline 24 & 36.5 & 44.5 & 270 & $\mathrm{E}$ & 112 & 270 & 9.6 & 49.8 & 30.2 & 21.2 & 64.0 \\
\hline Mean & 38.7 & 43.1 & 295 & & 52 & 283 & 9.3 & 53.6 & 35.0 & 24.2 & 73.8 \\
\hline SD & 2.3 & 1.7 & 55 & & 40 & 175 & 2.3 & 4.3 & 8.0 & 7.3 & 20.7 \\
\hline \multicolumn{12}{|c|}{ Preterm CHT/EHB $(n=3)$} \\
\hline 25 & 34.5 & 37.0 & 260 & A & 5 & 250 & 4.3 & 67.0 & 54.5 & 42.1 & 105.0 \\
\hline 26 & 34.0 & 37.6 & 252 & A & 11 & 1380 & 7.3 & 64.0 & 40.5 & 29.0 & 92.0 \\
\hline 27 & 35.0 & 37.5 & 252 & A & 20 & $>60$ & 6.3 & 64.7 & 35.2 & 24.2 & 74.7 \\
\hline Mean & 34.5 & 37.4 & 255 & & 12 & $>563$ & 6.0 & 65.2 & 43.4 & 31.8 & 90.6 \\
\hline SD & 0.5 & 0.3 & 5 & & 8 & & 1.6 & 1.6 & 10.0 & 9.3 & 15.2 \\
\hline
\end{tabular}

* For group CHT/LHB, bilirubin at time of admission; for CHT/EHB, maximum bilirubin in first week.

$\dagger \mathrm{A}$, athyroidism; $\mathrm{E}$, ectopic gland; TB, total enzymatic block in thyronine synthesis; $\mathrm{PB}$, partial enzymatic block in thyronine synthesis.
$\ddagger \mathrm{CCT}$, central conduction time.

between the two peaks. The wave complex of the term CHT patients was less mature than that of the normal infants of the same PMA and resembled that of normal term neonates during the first week after birth. We did not observe abnormal wave forms in the SEP of preterm CHT patients.

\section{DISCUSSION}

Evoked potentials are particularly suited for a noninvasive evaluation of the integrity and functional maturation of a number of afferent pathways in the nervous system.

The conduction properties of the peripheral SEP pathway, as measured with N13/AL, are mainly determined by the diameter of the nerve fibers, thickness of the myelin sheet, internodal distance (19), and temperature (9). Peripheral nerve conduction velocity is reduced in untreated CHT infants $(20,21)$ and in preterm infants with a transient hypothyroxinemia (22). The conduction in the central pathway (N19, central conduction time, N32) is determined by maturational factors such as dentrite formation, synaptogenesis, and myelination and by factors such as sleep (16) and temperature $(9,19)$. Perinatal problems such as asphyxia (23), intraventricular hemorrhage $(24,25)$ and jaundice (13) can prolong the central conduction.
Because a lack of thyroid hormones results in reduced myelin (26), synapse (27), and dendrite formation (28), the occurrence of neurophysiologic abnormalities in untreated CHT patients is not unexpected. The majority of our CHT patients showed prolonged latencies and immature wave patterns. These data agree with earlier studies on untreated CHT infants of comparable age. In a SEP study, prolonged central conduction times were found after median nerve stimulation (12). A study on peripheral nerves of the lower limb revealed reduced peripheral nerve conduction velocities as well as prolonged Hoffmann's reflexes (21). A VEP study (11) in older untreated CHT infants yielded consistently prolonged latencies and immature wave forms, which slowly normalized under therapy. The authors concluded that the evoked potential abnormalities reflected the delay in CNS maturation caused by CHT.

The influence of temperature must also be considered because hypothermia in adult HT patients causes an additional slowing of the peripheral and central conduction (9). For that reason we were careful to keep the temperature of the arms at $36-37^{\circ} \mathrm{C}$.

Influence of jaundice and age. Neonatal jaundice is not rare in CHT. The incidence of EHB and LHB in our study agrees with earlier studies (14). In normal term neonates, hyperbilirubinemia influences the brainstem auditory evoked potential (29) and SEP 

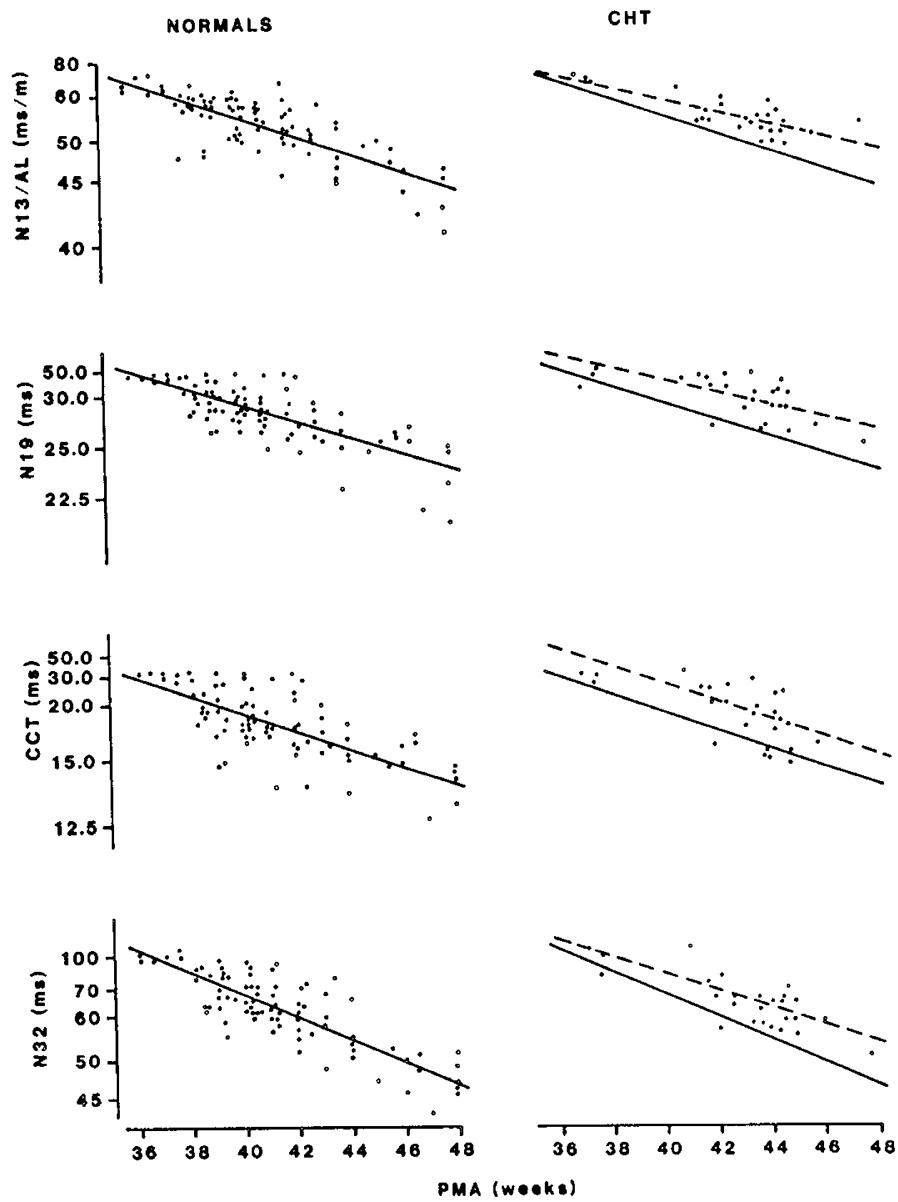

Fig. 1. The four SEP variables in relation to PMA. Solid lines, the regression lines of the reference population; broken lines, the regression lines of the CHT group.

Table 2. SEP lag, BA lag, $d S E P$, and $d B A$ values (mean \pm 1 $S D)$ of reference and $C H T$ groups*

\begin{tabular}{|c|c|c|c|}
\hline & \multirow{2}{*}{$\begin{array}{l}\text { Reference group } \\
\quad(n=103) \\
\text { SEP lag }\left(\mathrm{ms} \cdot 10^{2}\right) \dagger\end{array}$} & \multicolumn{2}{|c|}{$\mathrm{CHT}$ group $(n=27)$} \\
\hline & & SEP lag $\left(\mathrm{ms} \cdot 10^{2}\right) \dagger$ & $\mathrm{dSEP}(\mathrm{wk})$ \\
\hline \multicolumn{4}{|l|}{ SEP variable } \\
\hline N13/AL & $0.0 \pm 1.7$ & $1.8 \pm 1.2 \ddagger$ & $2.3 \pm 0.1 \S$ \\
\hline N19 & $0.0 \pm 1.9$ & $2.5 \pm 1.9 \neq$ & $3.1 \pm 0.9 \S$ \\
\hline $\mathrm{CCT}$ & $0.0 \pm 2.3$ & $2.3 \pm 2.2 \|$ & $2.3 \pm 0.8 \S$ \\
\hline \multirow[t]{2}{*}{ N32 } & $0.0 \pm 3.5$ & $3.5 \pm 2.7 \|$ & $2.1 \pm 0.7 \S$ \\
\hline & & BA lag (score) & $\mathrm{dBA}(w \mathrm{k})$ \\
\hline $\mathrm{BA}$ & & $3.2 \pm 2.2$ & $6.4 \pm 0.6$ \\
\hline
\end{tabular}

* dSEP, difference in weeks between SEP of CHT and reference group; $\mathrm{dBA}$, difference in weeks between BA of CHT and reference group; CCT, central conduction time.

$\uparrow \mathrm{N} 13 / \mathrm{AL}$ lag in $\mathrm{ms} \cdot \mathrm{m}^{-1} \cdot 10^{-2}$

$¥$ Significant difference with reference group, $p<0.0001$.

$\S$ Significant difference with $\mathrm{dBA}, p<0.0001$.

\| Significant difference with reference group, $p<0.001$.

(13) results, whereas the preterm SEP seems less affected (30). It is therefore not unexpected that in term CHT patients early jaundice caused an additional slowing of the various components of the SEP; late jaundice, however, did not. In our small preterm group, neither hyperbilirubinemia nor CHT gave significant SEP prolongations. With regard to the influence of jaundice, others reached the same conclusion studying normal preterm infants with comparable bilirubin values (30). Why CHT would affect preterm newborns less than term babies is unclear. Lower T4 values exist in normal preterm infants than in term neonates; nevertheless, normal preterm infants' neural maturation progresses rapidly (22). For all SEP variables of the CHT infants, a progress in maturation was found from 36 to 48 wk PMA. However, for two variables the rate of maturation was less than that of the normal infants. This means that with increasing age SEP lag becomes more pronounced. This may indicate that the SEP abnormalities are age-dependent and that in CHT during the last weeks of a term or postterm gestational period CNS maturation slows down despite substantial transplacental T4 transfer (6) and continues to do so after birth. It is likely that a longer postnatal delay of treatment will cause a more severe delay in SEP maturation, but this cannot be concluded from our data because the variation in postnatal age (2-5 wk) was too small to allow significant regressions.

SEP maturation and $B A$. In our CHT neonates, BA delay exceeded SEP delay by several weeks. This is in accordance with clinical studies. In CHT patients investigated during the 1 st week of life (8), retarded BA and typical morphologic features such as a large tongue, dry hair, and a typical facies were identified as main indicators for CHT, whereas typical neurologic features of CHT like feeding difficulties, lethargy, and flaccidity were not. Moreover, neurologic maturation as measured with reflex patterns was mature (8). However, by the 3 rd week, the neurologic features were present in $33 \%$ of the CHT infants (31). These studies $(8,31)$, as well as our own study, support the hypothesis (32) that the negative effect of low T4 levels on the CNS is mitigated compared to the effect on, for instance, bone and skin tissue.

An explanation for this discrepancy may be found in the balance between the activity of the $5^{\prime} \mathrm{DI}$ and $5^{\prime}$ DII deiodinating systems in the CHT fetus and newborn. The 5'DII deiodinating system predominates in brain (33), brown adipose tissue (34), and homogenates of the chorionic membrane decidua of the placenta (35). The enhancement of this system in the case of low serum T4 values may explain the high local T3 production found in the cortex and cerebellum of newborn rats with HT $(36,37)$. Otherwise, the 5'DI system, more prevalent in liver, kidney, and muscle (38), is depressed in HT (36). If bone tissue like muscle tissue (38) belongs to the 5'DI compartment, it will be dependent on circulating T3 for its metabolism and maturation (37). This is low in severe HT. This hypothesis is supported by the weak but significant inverse relation between BA delay and T4 levels found by us and others (8). Our study suggests that SEP maturation provides a better estimation of the activity of the cerebral 5'DII system and, therefore, of the CNS maturation of the fetus than BA.

However, within the CHT group, serum T4 and SEP abnormalities showed a poor correlation. A SEP study on adult patients with HT also demonstrated an absent relation between $\mathrm{T} 4$ and the VEP prolongations (39); on L-T4 treatment the latencies shortened. This observation supports the hypothesis that the T4 deficiency was the main factor responsible for the delays, despite the absence of a direct relation. Such direct relation may have been disturbed by several factors: a nonlinear relation between serum T4 and the 5'DII activity, the interference of the T4 blood-brain barrier, a time lag between T4 and SEP alterations, and, in the case of neonatal CHT, the intrauterine T4 supply and the postnatal alterations in serum T4. Inasmuch as all of these factors are well outside the scope of our study, the exact nature of the relation between the evoked potential abnormalities and serum $\mathrm{T} 4$ remains to be elucidated.

In conclusion, the results of our study demonstrate a delay in neurophysiologic maturation of CHT infants at initiation of therapy. The delay, however, is less severe than BA delay. Preterm CHT patients are probably less affected than term patients. Jaundice during the first postnatal week in term infants has a clear additional adverse effect, whereas for LHB no such effect could be found. Our results are in line with the clinical observation that the neurologic development of most CHT infants 
Table 3. SEP lag $\left(m s \cdot 10^{2}\right)$ (mean and $95 \%$ confidence limits) of CHT and control groups with different types of hyperbilirubinemia*

\begin{tabular}{|c|c|c|c|c|c|c|}
\hline & \multicolumn{2}{|c|}{ Controls } & \multicolumn{4}{|c|}{$\mathrm{CHT}$} \\
\hline & $\begin{array}{l}\text { NonHB } \\
(n=18) \\
\end{array}$ & $\begin{array}{c}\text { EHB } \\
(n=10) \\
\end{array}$ & $\begin{array}{l}\text { NonHB } \\
(n=11) \\
\end{array}$ & $\begin{array}{c}\text { LHB } \\
(n=8)\end{array}$ & $\begin{array}{c}\text { Term EHB } \\
(n=5)\end{array}$ & $\begin{array}{c}\text { Preterm EHB } \\
(n=3)\end{array}$ \\
\hline N13/AL $\dagger$ & 0.2 & 1.6 & 1.8 & 2.2 & 2.0 & 0.8 \\
\hline $95 \%$ CL & $-0.4-0.8$ & $0.8-2.4$ & $1.1-2.5$ & $1.3-3.0$ & $0.9-3.0$ & $-0.5-2.2$ \\
\hline N19 & -0.1 & 1.9 & 2.4 & 2.7 & 4.1 & 0.1 \\
\hline $95 \% \mathrm{CL}$ & $-0.9-0.7$ & $0.8-3.0$ & $1.4-3.4$ & $1.5-3.9$ & $2.6-5.6$ & $-1.9-2.0$ \\
\hline CCT & -0.1 & 1.4 & 1.8 & 1.8 & 4.7 & 1.1 \\
\hline $95 \% \mathrm{CL}$ & $-1.0-0.9$ & $0.1-2.8$ & $0.6-3.0$ & $0.4-3.2$ & $2.9-6.5$ & $-1.2-3.4$ \\
\hline $\mathrm{N} 32$ & 0.5 & -0.03 & 2.5 & 4.6 & 5.7 & 0.6 \\
\hline $95 \% \mathrm{CL}$ & $-0.6-1.6$ & $-1.5-1.5$ & $1.1-4.0$ & $2.9-6.3$ & $3.5-7.9$ & $-2.2-3.4$ \\
\hline
\end{tabular}

* CL, confidence limit; CCT, central conduction time.

$\dagger \mathrm{N} 13 /$ AL lag in $\mathrm{ms} \cdot \mathrm{m}^{-1} \cdot 10^{-2}$.

NORMALS

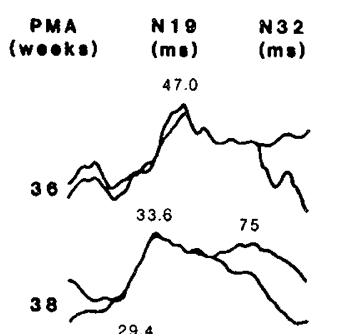

40

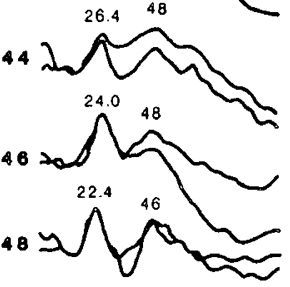

CHT and/Or EHB
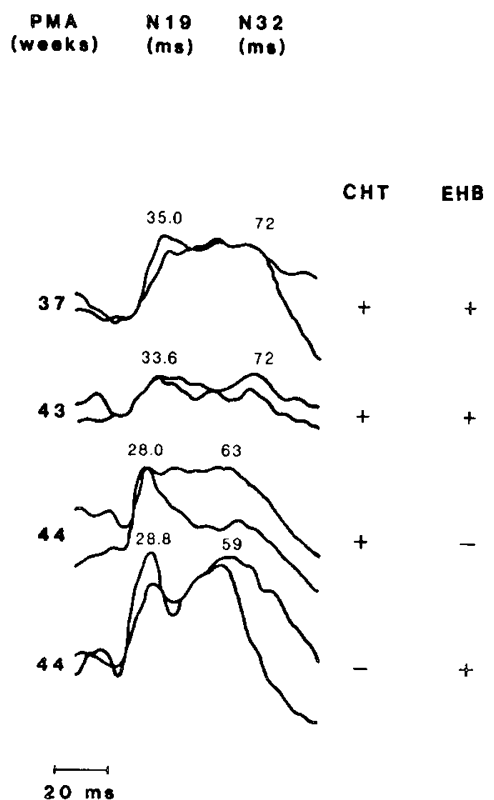

Fig. 2. Typical examples of cephalic SEP at the indicated PMA of normal (left panel) and CHT and/or EHB (right panel) infants. The results of the left and right hemisphere are superimposed. N19 and N32 peak latencies are indicated. Negative: upward.

shortly after birth is close to normal. This may explain why many of them, if treated early, grow up without neurologic handicap. However, in a number of them, the CNS development has apparently been disturbed, perhaps in late gestation and in early postnatal life, resulting in definitive damage to the CNS Therapy should therefore be started as early as possible. In infants with associated perinatal problems such as severe early jaundice, a more disturbed neurologic maturation may be expected.

\section{REFERENCES}

1. Mäenpää J 1972 Congenital hypothyroidism. Aetiological and clinical aspects. Arch Dis Child 47:914-923

2. Wolter R, Noël P, De Cock P, Crean M, Ernould CH, Malvaux P, Verstraeten F, Simons J, Mertens S, Van Broeck N, Vanderschueren-Lodeweyckx M 1979 Neuropsychological study in treated thyroid dysgenesis. Acta Paediat Scand [Suppl] 277:41-46

3. Murphy G, Hulse JA, Jackson D, Tyrer P, Glossop J, Smith I, Grant D 1986 Early treated hypothyroidism: development at 3 years. Arch Dis Child 61:761-765

4. Birrell J, Frost GJ, Parkin JM 1983 The development of children with congenital hypothyroidism. Dev Med Child Neurol 25:512-519

5. Vulsma T, Gons MH, de Vijlder JJM 1989 Maternal-fetal transfer of thyroxine in congenital hypothyroidism due to total organification defect or thyroid agenesis. N Engl J Med 321:13-16

6. New England Congenital Hypothyroidism Collaborative 1984 Characteristics of infantile hypothyroidism discovered on neonatal screening. J Pediatr 104:539-544

7. Glorieux J, Desjardins M, Letarte J, Morisette J, Dussault JH 1988 Useful parameters to predict the eventual mental outcome of hypothyroid children. Pediatr Res 24:6-8

8. Virtanen M 1988 Manifestations of congenital hypothyroidism during the first week of life. Pediatrics 147:270-274

9. Abbott RJ, O'Malley BP, Barnett DB, Timson L, Rosenthal FD 1983 Central and peripheral nerve conduction in thyroid dysfunction: the influence of $L-$ thyroxine therapy compared with warming upon the conduction abnormalities of primary hypothyroidism. Clin Sci 64:617-622

10. Ladenson PW, Stakes JW, Ridgway EC 1984 Reversible alteration of the visual evoked potential in hypothyroidism. Am J Med 77:1010-1014

11. Hrbek A, Fallstrom SP, Karlberg P, Olsson T 1982 Clinical application of evoked EEG responses in infants. III. Congenital hypothyroidism. Dev Med Child Neurol 24:164-172

12. Laureau E, Vanasse M, Hebert R, Letarte J, Glorieux J, Desjardins M, Dussault JH 1986 Somatosensory evoked potentials and auditory brain-stem responses in congenital hypothyroidism. I. A longitudinal study before and after treatment in six infants detected in the neonatal period. Electroencephalogr Clin Neurophysiol 64:501-510

13. Bongers-Schokking JJ, Colon EJ, Hoogland RA, Van den Brande JL, de Groot CJ 1990 Somatosensory evoked potentials (SEPs) in neonatal hyperbilirubinemia. Acta Paediatr Scand 79:148-155

14. Letarte J, La Franchi S 1979 Clinical features of congenital hypothyroidism. In: Dussault JH, Walker P (eds) Congenital Hypothyroidism. Marcel Dekker, Inc, New York, pp 351-383

15. Bongers-Schokking JJ, Colon EJ, Hoogland RA, Van den Brande JL, de Groot CJ 1989 The somatosensory evoked potentials of normal infants. Influence of filter bandpass, arousal state and number of stimuli. Brain Dev 11:33-39

16. Bongers-Schokking JJ, Colon EJ, Hoogland RA, Van den Brande JL, de Groot CJ 1990 Somatosensory evoked potentials in term and preterm infants in relation to postconceptional age and birth weight. Neuropediatrics 21:32-36

17. de Jonge H 1964 Inleiding tot de medische statistiek, 2nd Ed, Part II. WoltersNoordhoff, Groningen

18. Sénécal J, Grosse MC, Vincent A, Simon J, Lefreche JN 1977 Maturation osseuse du foetus et du nouveau-né. Arch Fr Pediatr 34:424-438

19. Wagner AL, Buchthal F 1972 Motor and sensory conduction in infancy and childhood: reappraisal. Dev Med Child Neurol 14:189-216

20. Moosa A, Dubowitz V 1971 Slow nerve conduction velocity in cretins. Arch Dis Child 46:852-854

21. de Vries LS, Heckmatt JZ, Burrin JM, Dubowitz LMS, Dubowitz V 1986 Low serum thyroxine concentrations and neural maturation in preterm infants. Arch Dis Child 61:862-866

22. Giroud M, Tenenbaum D, D'Athis Ph, Dumas R, Nivelon JL 1988 L'exploration neuro-pysiologique des nerfs péripheriques des nouveau-nés porteurs d'une hypothyréoidie congenitale. Arch Fr Pediatr 45:175-179

23. Hrbek A, Karlberg P, Kjellmer I, Olssen T, Riha M 1977 Clinical application of evoked electroencephalographic responses in newborn infants. I. Perinata asphyxia. Dev Med Child Neurol 19:34-44

24. Laget P, Salbreux R, Raimbault J, d'Allest AM, Mariani J 1976 Relationship between changes in somesthetic evoked responses and electroencephalographic findings in the child with hemiplegia. Dev Med Child Neurol 18:620 631

25. Klimach VJ, Cooke RWI 1988 Short-latency cortical somatosensory evoked responses of preterm infants with ultrasound abnormalities of the brain Dev Med Child Neurol 30:215-221

26. Rosman NP, Malone MJ 1977 Brain myelination in experimental hypothyroidism: morphological and biochemical observations. In: Gilman D (ed) Thyroid Hormones and Brain Development. Raven Press, New York, pp $169-198$

27. Nicholson JL, Altman J 1972 The effects of early hypo- and hyperthyroidism on the development of rat cerebellar cortex. II. Synaptogenesis in the molecular layer. Brain Res 44:25-36 
28. Eayrs JT 1955 The cerebral cortex of normal and hypothyroid rats. Acta Anat (Basel) 25:160-183

29. Nakamura H, Takada S, Shimabuku R, Matsuo M, Matsuo T, Negishi H 1985 Auditory nerve and brainstem responses in newborn infants with hyperbilirubinemia. Pediatrics 75:703-708

30. Pierrat V, de Vries LS, Minami T, Casaer P 1990 Somatosensory-evoked potentials and adaptation to extrauterine life: a longitudinal study. Brain Dev 12:376-379

31. Derksen-Lubsen G 1981 Screening for congenital hypothyroidism in the Netherlands. Thesis. Erasmus University, Rotterdam, pp 111-117

32. Morreale de Escobar G, Obregon MJ, Ruiz de Ona C, Escobar del Rey F 1989 Comparison of maternal to fetal transfer of $3,5,3^{\prime}$-triiodothyronine versu thyroxine in rats, as assessed from 3,5,3'-triiodothyronine levels in fetal tissues. Acta Endocrinol (Copenh) 120:20-30

33. Silva JE, Leonard JL 1985 Regulation of rat cerebrocortical and adenohypophyseal type II $5^{\prime}$-deiodinase by thyroxine, triiodothyronine and revers triiodothyronine. Endocrinology 116:1627-1635
34. Iglesias R, Fernandez JA, Mampel T, Obregon MJ, Villarroya F 1987 Iodothyronine 5 '-deiodinase activity in rat brown adipose tissue during development. Biochim Biophys Acta 923:233-240

35. Kaplan MM, Shaw EA 1984 Type II iodothyronine $5^{\prime}$-deiodination by human and rat placenta in vitro. J Clin Endocrinol Metab 59:253-257

36. Silva JE, Larsen PR 1982 Comparison of iodothyronine 5'-deiodinase and other thyroid-hormone-dependent enzyme activities in the cerebral cortex other thyroid-hormone-dependent enzyme activities in the cerebral cortex
of hypothyroid neonatal rat. Evidence for adaptation to hypothyroidism. $\mathbf{J}$ Clin Invest 70:1110-1123

37. Van Doorn J, Roelfsema F, van der Heide D 1982 Contribution from local conversion of thyroxine to 3,5,3'-triiodothyronine to intracellular 3,5,3'triiodothyronine in several organs in hypothyroid rats at isotope equilibrium. Acta Endocrinol (Copenh) 101:386-396

38. Chopra IJ 1977 A study of extrathyroidal conversion of thyroxine (T4) to 3,3',5-triiodothyronine (T3) in vitro. Endocrinology 101:453-463

39. Mastaglia FL, Black JL, Collins DWK, Guttenridge DH, Yuen RWM 1978 Slowing of conduction in visual pathway in hypothyroidism. Lancet 1:387388 